\title{
DESIGN ANALYSIS OF AUTOMOBILE MUFFLER WITH CAVITY
}

\author{
GIRISH BHIOGADE ${ }^{1}$, K. YUVAKIRAN VARMA ${ }^{2}$, PRASENJIT RANA ${ }^{3} \&$ S. P. CHINCHOLKAR ${ }^{4}$ \\ ${ }^{1,2,3}$ Vignan Institute of Information Technology, Visakhapatnam, India - 530049 \\ ${ }^{4}$ Kavikulguru Institute of Technology and Science Ramtek, Nagpur, India - 441106
}

\begin{abstract}
The reduction of the emitted noise pollution from the exhaust system of the engines is a real challenge for various industries. In this regard, mufflers have been used to reduce the transmitted noise from the automobile engine into the surrounding environment. Mufflers are designed to reflect the sound waves produced by the engine in such a way that they partially cancel themselves out. Noise transmission loss performance in muffler depends on its geometry. Therefore, maximization of noise transmission loss in mufflers using shape modification concept is an important research area. In this study, three approaches have been followed for the maximization of noise transmission loss in mufflers by using of shape modification concept i.e. including the resonators outside the expansion chamber, performance comparison for the mufflers with and without the resonators, calculations for transmission loss and modal analysis carried out in Ansys Mechanical APDL. Finally, the optimum shape of muffler based on the design variables for having maximum noise transmission loss is considered better.
\end{abstract}

KEYWORDS: Frequency, Muffler, Resonator, Silencer, Transmission Losses

Received: Jun 08, 2020; Accepted: Jun 28, 2020; Published: Sep 11, 2020; Paper Id.: IJMPERDJUN20201158

\section{INTRODUCTION}

The greatest source of noise which disturbs the people and creates impact on environment comes from transport vehicles. Internal combustion engines is one of the major sources of noise pollution. Generally, engine exhaust noise is the most dominant source compared to other sources of noise. The noise from an engineradiatesfrom sources associated with mechanical impacts and fluid flow processes. A high intensity pressure wave generated by combustion in the engine cylinder propagates along the exhaust pipe and radiates from the exhaust pipe termination. Noise contribution from various automotive systems shows that $32 \%$ of the overall noise produced by any engine is from the engine exhaust system. Generally, engines produce noise of 90 to $130 \mathrm{~dB}$ depending on the size and the type of the engine. Noise levels more than $80 \mathrm{~dB}$ are injurious to human, Hence to reduce noise frominternal combustion engines, they are equipped with an important noise control element known as silencer or muffler which suppresses the acoustic pulse generated by the combustion process. Muffler/silencer is an important noise control element for reduction of exhaust noiseand other noise sources involving flow of the exhaustgas.

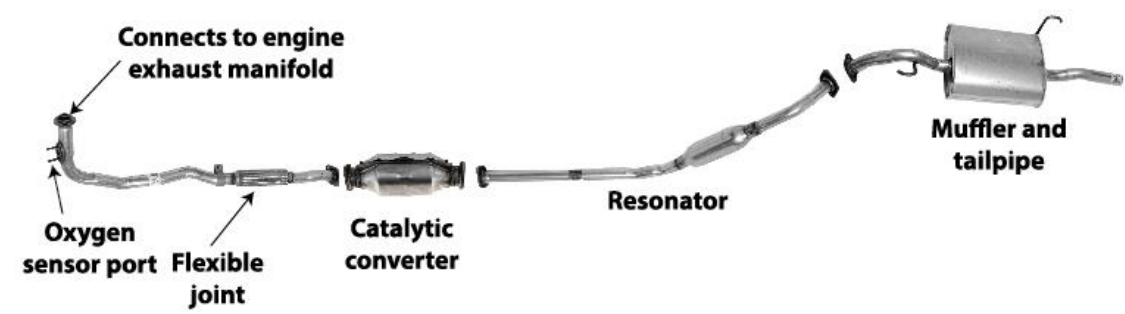

Figure 1: Vehicle Exhaust System with Resonator and Muffler. 
The basic construction of muffler usually consists of the tubular metal jacket, perforated tubes and the expansion chamber. The arrangement of these components will guide the exhaust gas to flow from the inlet pipe of the muffler to the outlet (tailpipe). Mufflers are classified as dissipative or reactive, depending on whether the acoustic energy is dissipated into heat or isreflected back to form destructive interference and impedance mismatch by the area discontinuity. Simple reactive muffleris a simple expansion chamber, the simplest of the muffler configurations, has very limited practical application due to the presence of periodictroughs in the transmission loss spectrum which drastically lower the overall transmission loss of the muffler.

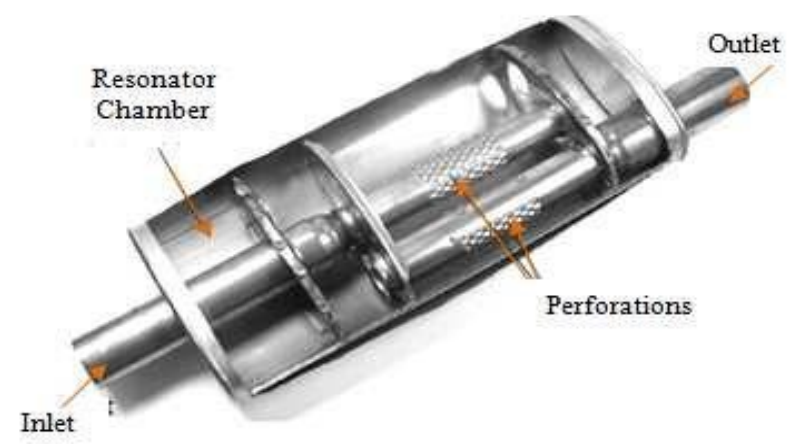

Figure 2: Schematic View of Reactive Muffler.

A reactive muffler as shown above, generally consists of a series of resonating and expansion chambers that are designed to reduce the sound pressure levels at certain frequencies. The inlet and outlet tubes are generally offset and have perforations thatallowsound pulses to scatter out in numerous directions inside a chamber resulting in destructive interference. Reactive mufflers are generally used to attenuate pressure pulsations since the smallholes and porousmaterials of dissipative mufflers may become clogged with deposits. The downside to reactive muffler is that larger back pressures are created.

The advantage of dissipative or absorptive muffler is low back pressure with are latively simple design. The inconvenience of this method is low sound damping ability compared to the other techniques, especially at low frequency.A typical absorptive muffler consists of a straight, circular and perforated pipe that is encased in a larger steel housing. Between perforated pipe and the casing isa layer of sound absorptive material that absorbssome of the pressure pulses. Absorptive mufflers createless back pressure then reactive mufflers; however, they reduce noise as well. Absorptive mufflers use sound absorbing materials to attenuate sound waves.

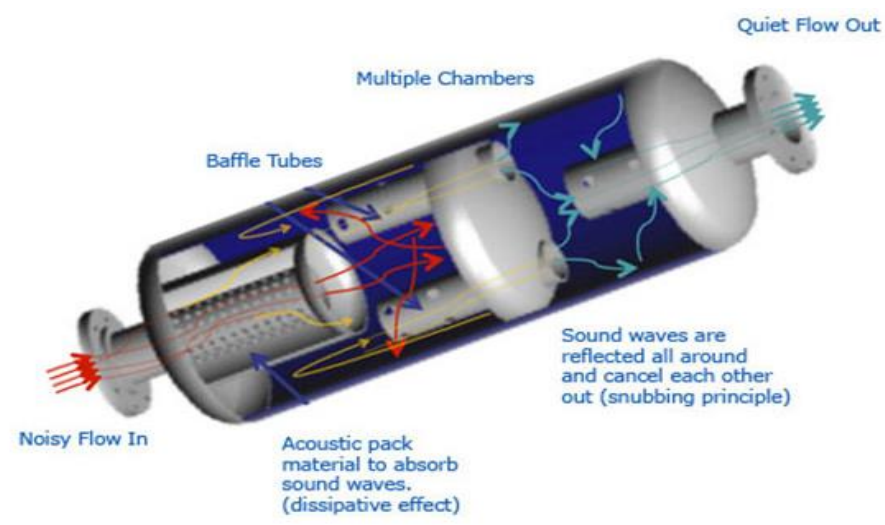

Figure 3: Schematic View of Absorption or Dissipative Type Muffler. 
Vijay M Mundhe et al [1] depicts, muffler is an important part of an engine system used in exhaust system to reduce exhaustgas noise level. UjjalKalita et al [2] found that the Use of sound absorption material in an exhaust system dissipates the energy of the acoustic waves into heat and also store heat energy from the exhaust stream. Suresh P. M. et al [3] in his experimental modal analysis, deals with the determination of natural frequencies, damping ratios, and mode shapes through vibration testing found that the exhaust muffler in an automobile plays an integral role in reducing the sound of the automobile. Jigar H. Chaudhari et al [4] represent the review on different types of mufflers and design of exhaust system belonging engine and they concluded that the absorptive muffler design uses only absorption of the soundwave to reduce the noise level without messing with the exhaust gas pressure. M. Rahman et al [5] describes the absorptive muffleris the classic dissipative design, derivingits noise control properties from the basic fact that noise energyis effectively "absorbed" by various types of fibrous packing materials. Munjal ML. [6] represents the acoustics formulation of Ducts and Mufflers with Application to Exhaust and Ventilation System Design and reveals the variation of transmission loss in muffler by using different absorption materials as the main component for reduction of noise in muffler. Monkewitz and VO [7] studied two- and three-dimensional Helmholtz resonator models by externally exciting them using a plane wave while much of the literature on classical single orifice HR has focused on the development of end correction factors for calculating the correct natural frequency. Shantanu V et al [8] depicts the optimization of sound transmission loss of single chamber perforated muffler with straight duct and Evaluation \& Comparative Analysis of Transmission Loss Using Different Types of Silencers using Analytical, Computational \& Experimental Technique. Chiu, M. C.et al [9] gives the new techniques of multi-chambermufflersequippedwith a sideinlet and internal non perforatedintruding tubes however, the research work of multi chamber mufflers in conjunction with side inlet and openendedperforated intruding tubes. Bing, W.et al [10]builds the model and theoretically studies and analyzes the internal sound problem and contrasts between FEM and transmission matrix method and computes transmission loss. Chanaud R. $\mathrm{C}$ et al [11] depicts the characteristic property of the resonatoris its ability to absorb soundwaves of a particular frequency, the so-called resonance frequency. Therefore, in practical applications, itis important to determine the resonancefrequency and absorption properties of the system as precisely and has found application in a widevariety of technologically significant problems Essentially, the resonatoris a cavity of relatively large volume connected with the outside space through an orifice or neck.

Although the study of mufflers, particularly those used with reciprocating combustion engines, has been of interest for many years, the increased public awareness of noise issues and stringent regulations have provided an impetus to improve the performance of these devices. A large amount of work has been published since then on the basis of the plane wave theory for the prediction of muffler performance.

The objectives of the present work are as follows:

- Develop numerical models for reactive mufflers with side outlet.

- Develop general ANSYS program to study acoustic behaviour of single and double chamber muffler by nodal elemental analysis and validation of program for various silencers. 


\section{RESULTS AND DISCUSSIONS}

Here dynamic modal analyses were carried out to determine the mode shapes, stresses and deformations of exhaust muffler using Ansys APDL analysis. Generally, we design Helmholtz resonator by analyzing in both numerical as well as experimental ways.

\section{Numerical Modelling}

The authors have used commercial finite element software ANSYS to model the resonator. The ANSYS Mechanical APDL workflow, graphical user interface, along with the APDL command syntax will be introduced to users. The design of Helmholtz resonator mainly depends on the volume of neck. So, we have analysed our device in this software with and without necks and the peak frequencies are obtained.
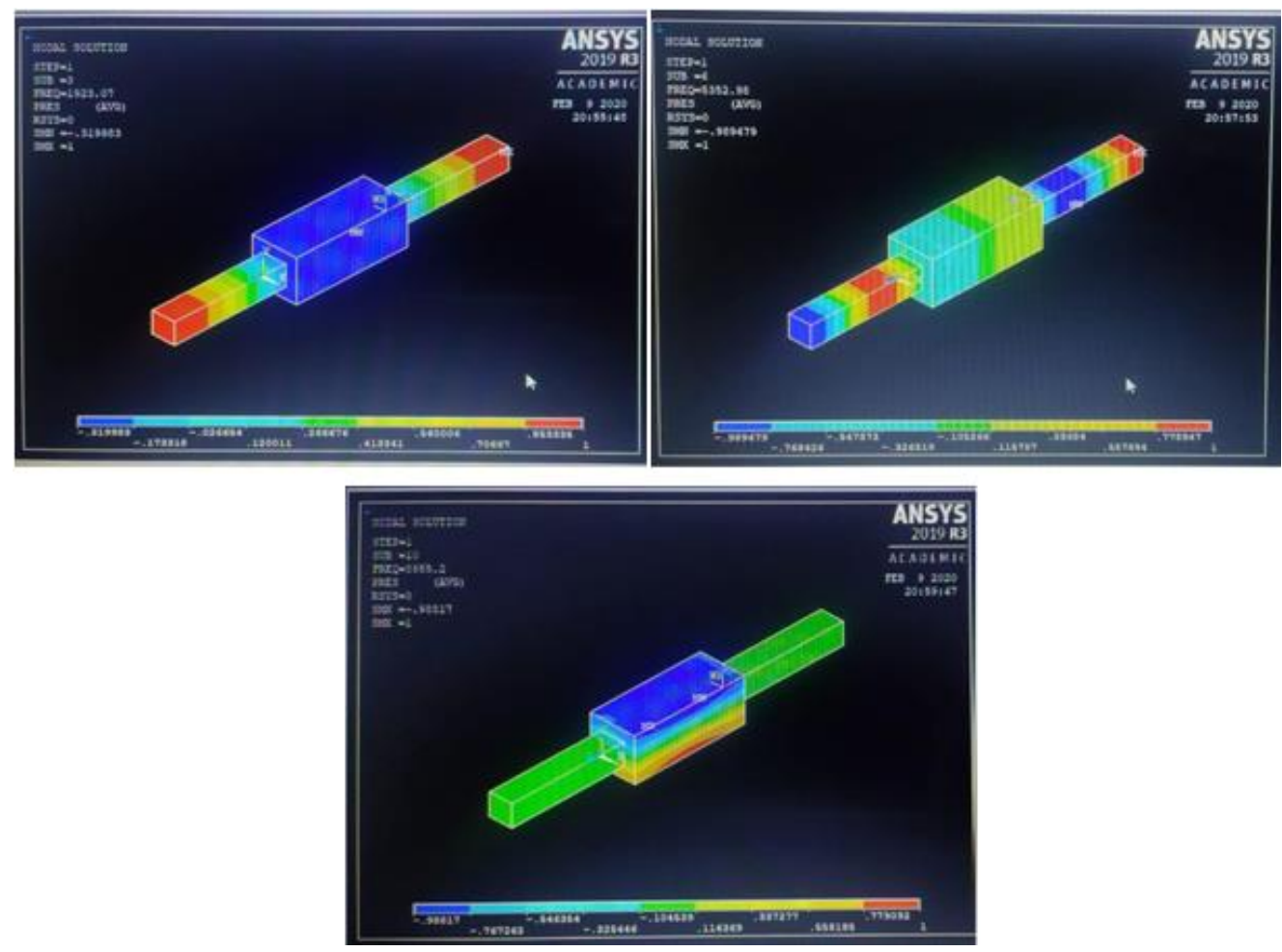

Figure 4: Ansys APDL Analysis at Different Frequencies.

\section{MUFFLER DESIGN}

\section{Input Parameters for Muffler Design}

- Inlet pipe diameter $(\mathrm{d})=25 \mathrm{~mm}$

- $\quad$ No. of cylinders $(n)=1$

- $\quad$ Operating frequency in $(\mathrm{Hz})=40 \mathrm{~Hz}, 70 \mathrm{~Hz}, 125 \mathrm{~Hz}, 200 \mathrm{~Hz}, 250 \mathrm{~Hz}, 300 \mathrm{~Hz}, 370 \mathrm{~Hz}, 470 \mathrm{~Hz}, 550 \mathrm{~Hz}$.

\section{Chamber Design}

- $\quad$ Length range in between

- $10 \mathrm{~d} \leq \mathrm{h} \leq 16 \mathrm{~d}$ 
- $\quad 0.25 \mathrm{~m} \leq \mathrm{L} \leq 0.4 \mathrm{~m}$

According to ASHRAE tech. committee,

\section{Chamber Diameter}

- $\quad(\mathrm{D} 1)=3 \mathrm{~d}$

- $75 \mathrm{~mm}=0.075 \mathrm{~m}$

\section{Calculations by Theoretical Formulae}

For engine frequencies $c=f \lambda$

Table 1

\begin{tabular}{|c|c|c|c|}
\hline Wave Length $(\boldsymbol{\lambda})$ & Sound Velocity $\mathbf{c}(\mathbf{m} / \mathbf{s})$ & Frequency $\mathbf{f}(\mathbf{H z})$ & $\lambda=\mathbf{c} / \mathbf{f}$ \\
\hline$\lambda 1$ & 343 & 370 & $0.927 \mathrm{~m}$ \\
\hline$\lambda 2$ & 343 & 470 & $0.729 \mathrm{~m}$ \\
\hline$\lambda 3$ & 343 & 550 & $0.623 \mathrm{~m}$ \\
\hline
\end{tabular}

\section{Chamber Length}

- Chamber $1: \lambda=\lambda_{1} / 4=0.23175 \mathrm{~m}$

- Chamber 2: $\lambda=\lambda_{2} / 4=0.18225 \mathrm{~m}$

- Chamber 3: $\lambda=\lambda_{3} / 4=0.15575 \mathrm{~m}$

As only the length of the chamber must be in a range of $0.25 \mathrm{~m} \leq \mathrm{L} \leq 0.4 \mathrm{~m}$, we consider only chamber 2 and chamber 3 and a resonator is made in place of chamber 1 of $\mathbf{3 7 0 H z}$.

Total length of muffler $=$ Length of chamber $2+$ Length of chamber $3=0.182 \mathrm{~m}+0.156 \mathrm{~m}=338 \mathrm{~mm}$ (or) $0.338 \mathrm{~m}$

Shell thickness $=1.5 \mathrm{~mm}$

Frequency $(f)=\frac{343}{2 \pi} \sqrt{\frac{a}{V L e q}}$

Area $(\mathrm{a})=\pi \mathrm{r}^{2}$

Chamber volume $(v)=\pi R^{2} H$

Leq $=\mathrm{L}+\delta$ in $+\delta$ out

$\delta_{\text {out }}=\frac{8 r}{3 \pi}$

$\delta_{\text {in }}=0.85 \mathrm{r}\left[1-1.25 \frac{r}{R}\right]$

Resonators are to be made for frequencies of $40 \mathrm{~Hz}, 70 \mathrm{~Hz}, 125 \mathrm{~Hz}, 200 \mathrm{~Hz}, 250 \mathrm{~Hz}, 300 \mathrm{~Hz}$, and $370 \mathrm{~Hz}$.

As of no availability of space only two resonators that are of frequency $370 \mathrm{~Hz}$ and $300 \mathrm{~Hz}$ can be accommodated. 


\section{Transmission Loss for the Muffler}

Transmission loss for the muffler without resonators is given as,

$$
\begin{aligned}
& \left.\mathrm{TL}=\left[10 \log \left[1+\frac{(1-1 / m)^{2}}{4}\right] \sin ^{2} k l\right)\right] \ldots \text { (i) } \\
& \mathrm{r} 13=\frac{A_{1}}{A_{3}}=1 \\
& \mathrm{r} 23=\frac{A_{2}}{A_{3}}=\left(\frac{r_{2}}{r_{3}}\right)^{2}=\mathrm{m} \omega=2 \pi f \ldots(i i) \\
& \mathrm{r}_{12}=\frac{A_{1}}{A_{2}}=\left(\frac{r_{1}}{r_{2}}\right)^{2}=\frac{1}{m} \mathrm{k}=\frac{\omega}{c} \ldots \text { (iii) }
\end{aligned}
$$

at frequency $550 \mathrm{~Hz}$

$$
\mathrm{r} 13=\frac{A_{1}}{A_{3}}=1
$$

$\mathrm{r} 23=\frac{A_{2}}{A_{3}}=\left(\frac{r_{2}}{r_{3}}\right)^{2}=9$

$$
\mathrm{r} 12=\frac{A_{1}}{A_{2}}=\left(\frac{r_{1}}{r_{2}}\right)^{2}=\frac{1}{9}
$$

substitute $\mathrm{f}=550 \mathrm{~Hz}$ in eq(i) we get,

therefore, $\mathbf{T L}=\mathbf{2 0 . 5 3 3 \mathrm { dB }}$

at frequency $470 \mathrm{~Hz}$,

$\mathrm{r}_{13}=\frac{A_{1}}{A_{3}}=1$

$\mathrm{r}_{23}=\frac{A_{2}}{A_{3}}=\left(\frac{r_{2}}{r_{3}}\right)^{2}=9$

$\mathrm{r}_{12}=\frac{A_{1}}{A_{2}}=\left(\frac{r_{1}}{r_{2}}\right)^{2}=\frac{1}{9}$

substitute $\mathrm{f}=470 \mathrm{~Hz}$ in eq (i) we get,

therefore, $\mathbf{T L}=\mathbf{1 5 . 9} \mathrm{dB}$

Transmission loss for resonators is given as

$$
\begin{aligned}
& \mathrm{TL}=\left[10 \log \left[1+\frac{c / 2 s}{\frac{\omega L}{s_{b}}-\frac{c^{2}}{\omega v}}\right]^{2}\right] \ldots \text { (i) } \\
& \mathrm{v}=\text { volume of resonator }=\mathrm{HxS} \\
& \mathrm{C}=343 \mathrm{~m} / \mathrm{s} \\
& \mathrm{L}^{\prime}=\mathrm{Leq}=1+\delta_{\text {in }}+\delta_{\text {out }}
\end{aligned}
$$


$\omega=2 \Pi \mathrm{f}$

For a resonator of $\mathbf{3 7 0 H z}$ frequency,

Substitute, $\omega=2 п \times 340, c=343 \mathrm{~m} / \mathrm{s}, \mathrm{f}=370 \mathrm{~Hz}$ in equation (1) we get,

$\mathbf{T L}=\mathbf{0 . 5 5 5 \mathrm { dB }}$

For a resonator of $\mathbf{3 0 0 H z}$ frequency,

Substitute, $c=343 \mathrm{~m} / \mathrm{s}, \mathrm{f}=300 \mathrm{~Hz}$ in equation (1) we get,

$\mathrm{TL}=\mathbf{0 . 4 2 3 7} \mathrm{dB}$

Therefore the transmission loss for a muffler without resonator is given as

Transmission loss of chamber $1(550 \mathrm{~Hz})+$ Transmission loss of chamber $2(470 \mathrm{~Hz})=20.533 \mathrm{~dB}+15.9 \mathrm{~dB}$

TL without resonator $=36.43 \mathrm{~dB}$

The transmission loss for a muffler with resonator is given as

Transmission loss of chamber $1(550 \mathrm{~Hz})+$ Transmission loss of chamber $2(470 \mathrm{~Hz})+$ Resonator $1(370 \mathrm{~Hz})+$ Resonator $2(300 \mathrm{~Hz})=20.533 \mathrm{~dB}+15.9 \mathrm{~dB}+0.555 \mathrm{~dB}+0.4237 \mathrm{~dB}$

TL with resonator $=37.4087 \mathrm{~dB}$

By the transmission loss obtained as above, we find that the transmission loss is maximum for the muffler with the resonators placed and hence the muffler with the resonators placed within the chamber has an ample amount of reduction in noise as compared to the mufflers without presence of resonators.

\section{MODAL ANALYSIS USING ANSYS APDL}

\section{Pressure Distribution Analysis with and without Resonators}

The following finite elemental analysis is carried out and the nodal solutions are obtained with the presence of resonators placed within the chamber and outside the chamber using the Ansys Mechanical APDL package.

The pressure distribution analysis results are shown in the figures below:

\section{Subset 1}

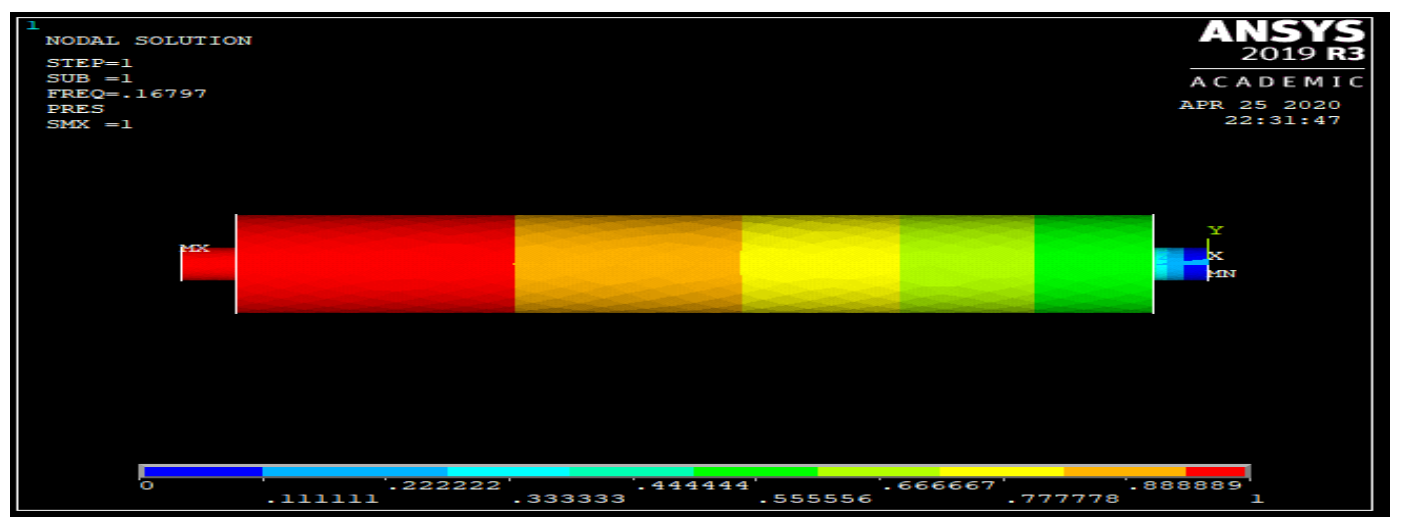

Figure 5: Pressure Distribution Analysis without Resonators. 


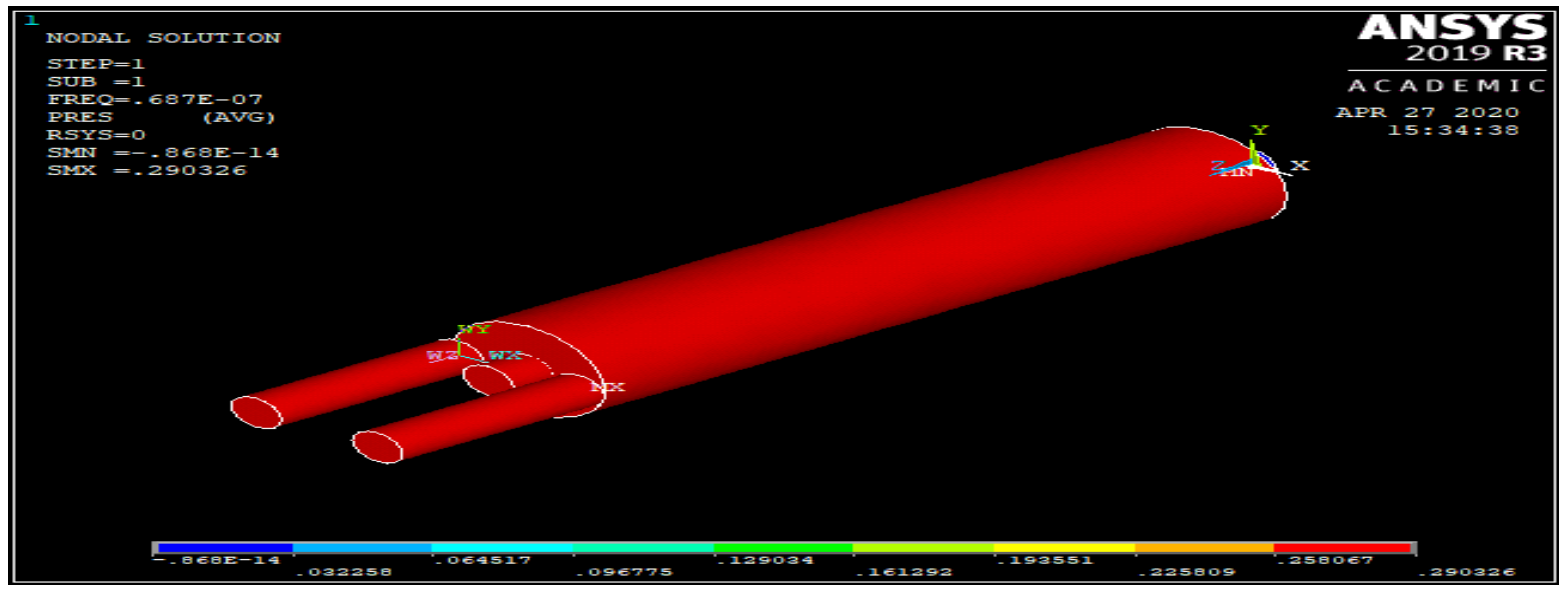

Figure 6: Pressure Distribution Analysis with Resonators.

Subset 2

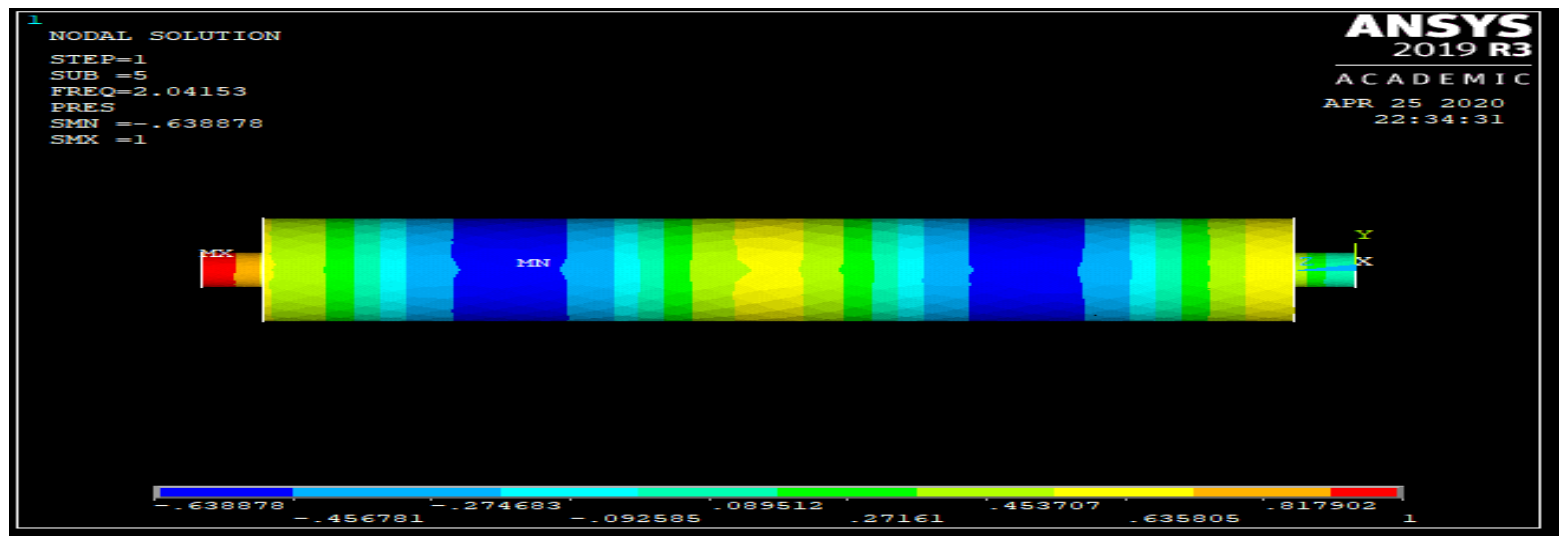

Figure 7: Pressure Distribution Analysis without Resonators.

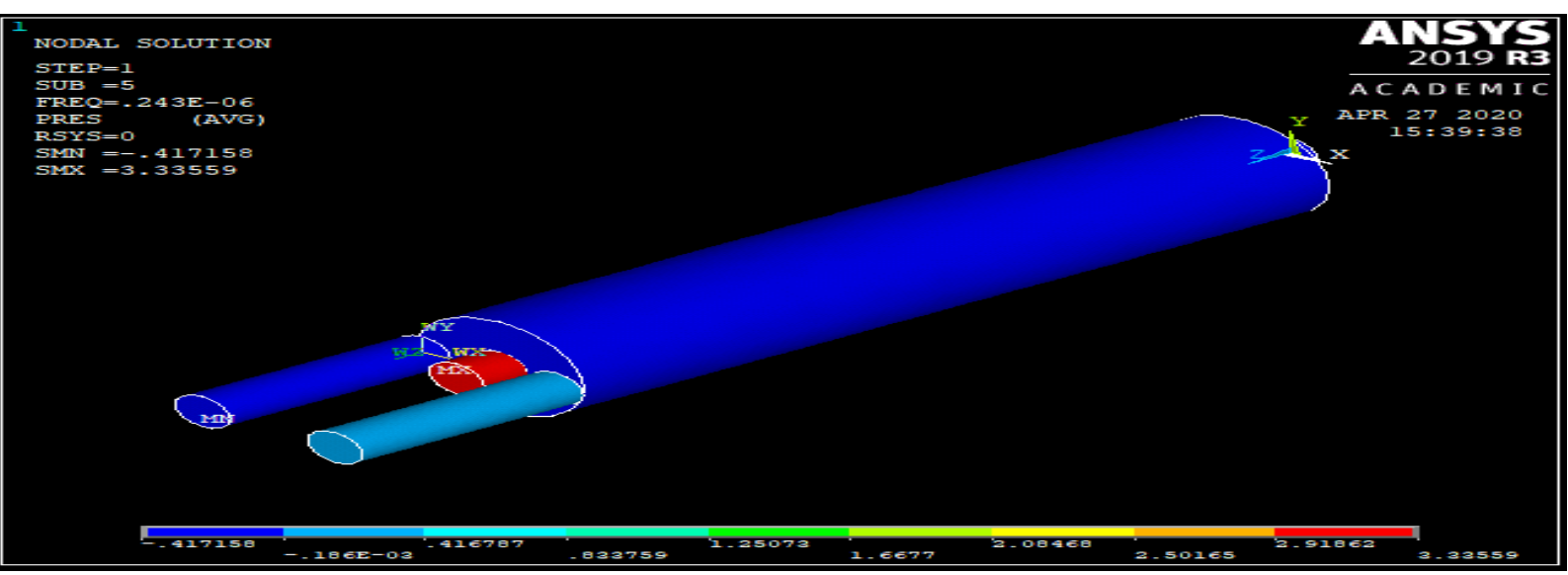

Figure 8: Pressure Distribution Analysis with Resonators. 


\section{Subset 3}

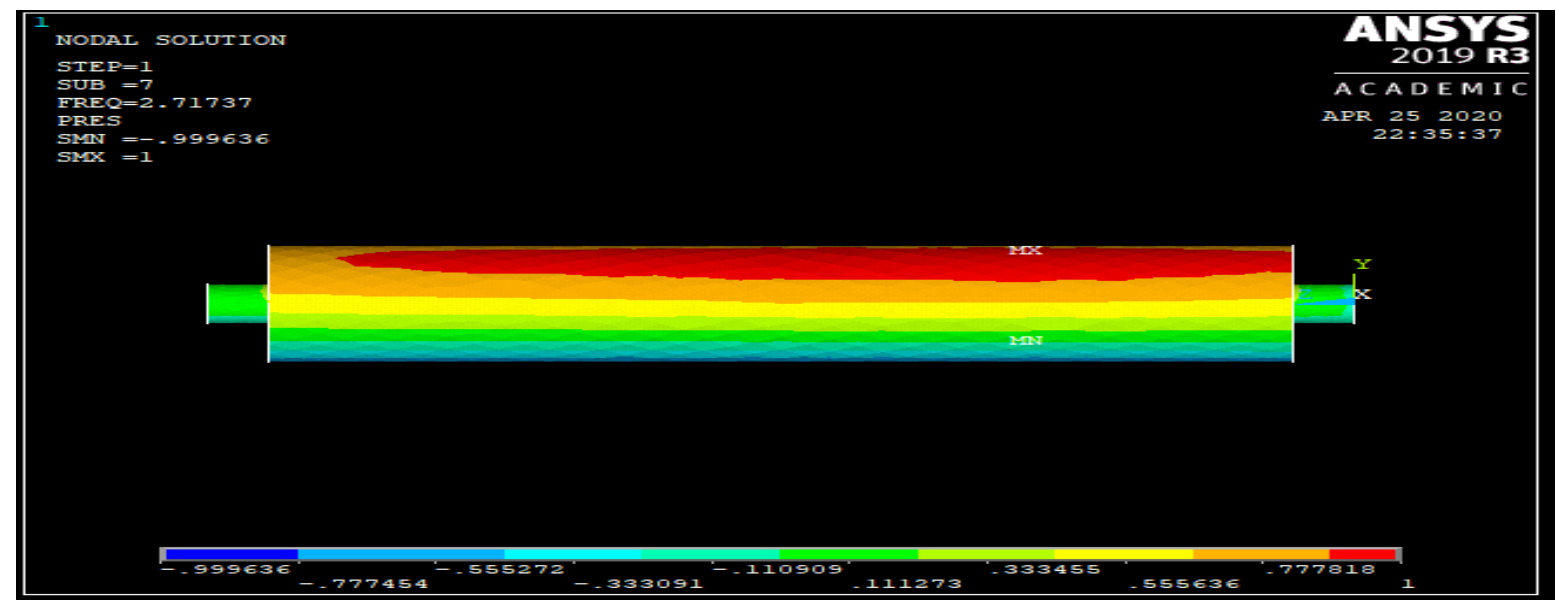

Figure 9: Pressure Distribution Analysis without Resonators.

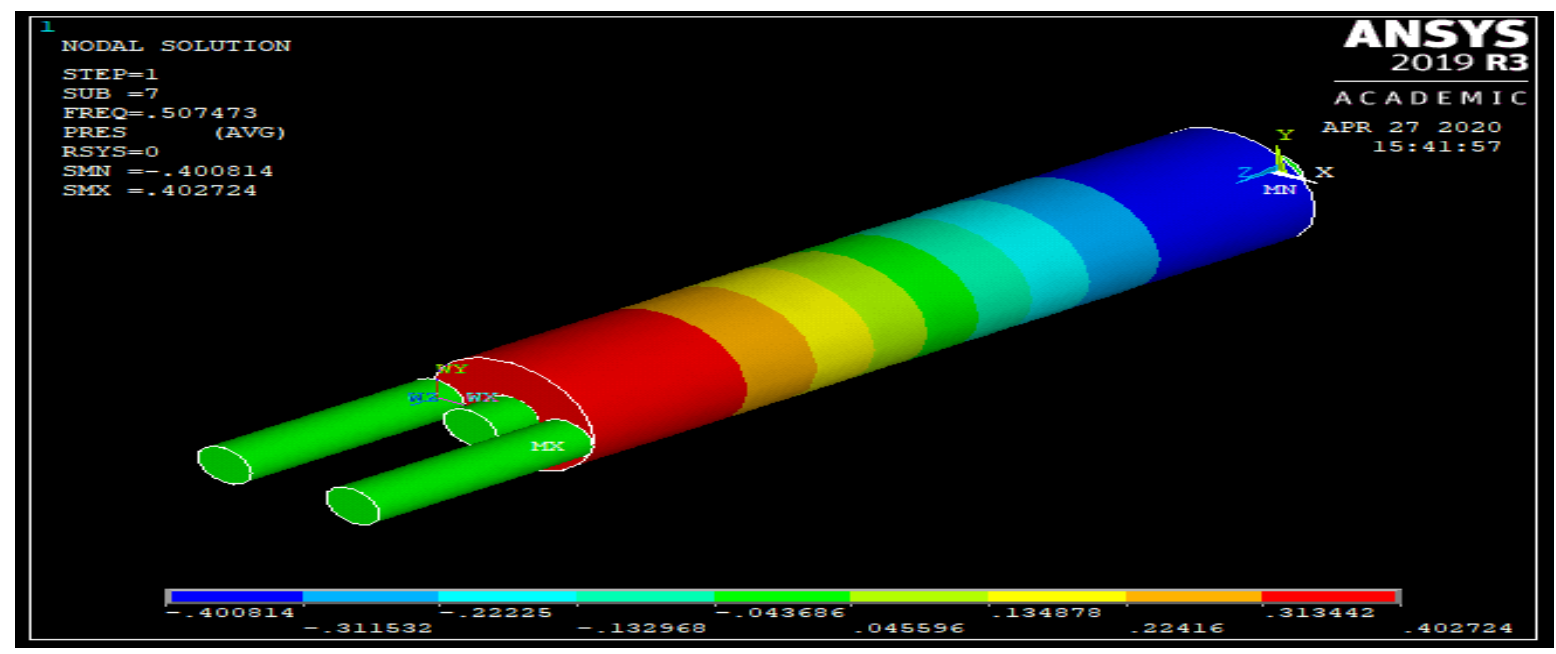

Figure 10: Pressure Distribution Analysis with Resonators.

\section{CONCLUSIONS}

- It can be concluded that the above analysis is useful to calculate the transmission losses, insertion losses, and the noise reduction.

- These methods are further used to minimise the losses and increase the efficiency.

- By this experiment it is possible to illustrate the relationship of the resonance frequency to the cavity volume of the Helmholtz resonator.

\section{REFERENCES}

1. Vijay M Mundhe, Eknath R Deore (2015), "Design and analysis of perforated muffler in Automobile Exhaust System" International Journal of Multidisciplinary Research and Development, Volume: 2, Issue: 7, (pp. 182-187)

2. UjjalKalita and AbhijeetPratap( 2015), “Absorption Materials Used In Muffler A Review” International Journal of Mechanical and Industrial Technology ISSN 2348-7593 Vol. 2,Issue 2, (pp. 31-37),

3. Sunil and Suresh P M (2014), "Experimental Modal Analysis Of Automotive Exhaust Muffler Using Fem And FFT Analyzer" International Journal of Recent Development in Engineering and Technology Volume 3 Issue 1, (pp. 185-187) 
4. Umesh, K. S., V. K. Pravin, and K. Rajagopal. "Experimental Investigation and CFD Analysis of Multi-Cylinder Four Stroke SI Engine Exhaust Manifold for Optimal Geometry to Reduce Back Pressure and to Improve Fuel Efficiency." International Journal of Automobile Engineering Research and Development, 4, 1320 (2014).

5. J. H. Chaudhari (2014), "Muffler design for automotive exhaust noise attenuation-A review" International Journal of Engineering Research and application, ISSSN:2248-9622, Vol. 4,(pp.220-223)

6. M. Rahman (2005), "Design and Construction of a Muffler for Engine Exhaust Noise Reduction” International Conference on Mechanical Engineering December 2005.

7. Sankarlal, Sathyaraj, and Venkatesan Kuppusamy. "Fabrication of Aluminium 6061-Sic-Al2o3 Mmc and Hmmc By Stir Casting Technique and Comparing the Mechanical Properties. "International Journal of Mechanical and Production Engineering Research and Development (IJMPERD) 8.1, Feb 2018, 635-642

8. Munjal, M. L. (1997). Plane Wave Analysis of Side Inlet/Outlet Chamber Mufflers with Mean Flow, Applied Acoustics, Vol. 52, (pp. 165-175).

9. Monkewitz and VO (1985) et al "The response to Helmholtz resonators to external excitations Part1- single resonators. "Cambridge University Press, (pp. 477-497)

10. Kumar, Rajat., Supreet. Singh, and Manpreet. Kaur. "Emission testing of catalytic converter using zirconium oxide (ZrO) and cobalt oxide (CoO) as catalyst." Int. J. Mech. Prod. Eng. Res. Dev 7 (2017): 333-342.

11. Shantanu V. Kanade, A. P Bhattu (2015), "Optimization of sound transmission loss and prediction of insertion loss of single chamber perforated plug muffler with straight duct”, American International Journal of Research in Science, Technology, Engineering \& Mathematics, Volume 6 (1), (pp. 13-19)

12. Das, Sucheta., et al. "Magnetic susceptibility of road dust from Kolkata-in relationship to road traffic." International Journal of Applied and Natural Science, 6 (5) (2017): 65-78.

13. Chiu, M. C., Yeh, L. J., Chang, T. C., \& Lan, T. S. (2009), "Shape Optimization ofSingle-Chamber Mufflers With Side Inlet/Outlet By Using Boundary Element Method, Mathematic Gradient Method and Genetic Algorithm”, Tamkang Journal of Science and Engineering, Vol. 12, No. 1, (pp. 85-98)

14. Bing, W., Yongjuan, W., \& Cheng, X. (2013). "Study of Transmission Loss on Muffler”, Research Journal of Applied Sciences, Engineering and Technology 5(24) (pp. 5556-5560).

15. Chanaud, R. C. (1994), "Effects of geometry on the resonance frequency of Helmholtz Resonators", Sound and Vibration, 178(3), (pp.337-348). 